\title{
Erratum: Climate change and the ownership of game: A concern for fenced wildlife areas
}

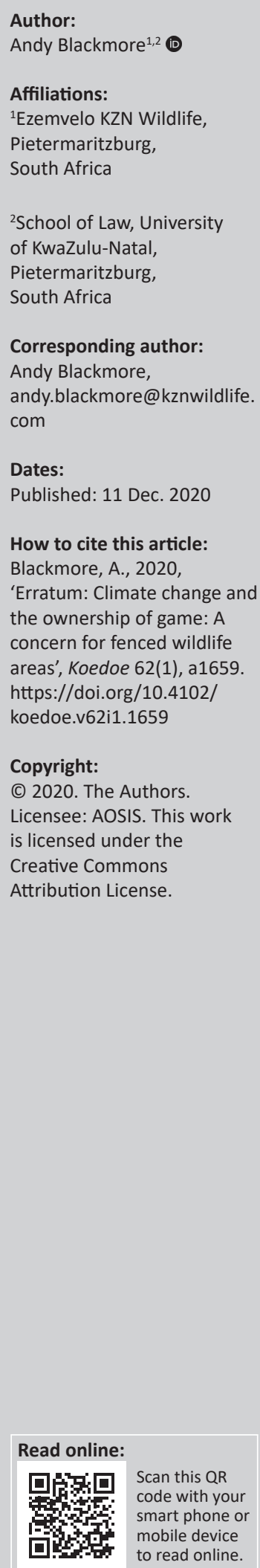

Scan this QR code with your smart phone or

In the version of this article initially published, Blackmore, A., 2020, 'Climate change and the ownership of game: A concern for fenced wildlife areas', Koedoe 62(1), a1594. https://doi. org/10.4102/koedoe.v62i1.1594, the author's second affiliation was omitted in the 'Authors' and 'Affiliations' sections. The author affiliations are now corrected as:

${ }^{1}$ Ezemvelo KZN Wildlife, Pietermaritzburg, South Africa

${ }^{2}$ School of Law, University of KwaZulu-Natal, Pietermaritzburg, South Africa

This correction does not alter the study's findings of significance or overall interpretation of the study's results. The publisher apologises for any inconvenience caused. 